\title{
OCUPAÇÃO E ESCRAVIDÃO EM MOÇAMBIQUE DO SÉCULO XIX ${ }^{1}$
}

\author{
Francielly Giachini Barbosa ${ }^{2}$
}

Resumo: Discutir questões relacionadas à ocupação e ao tráfico de escravos em Moçambique ao longo do século XIX é a intenção deste texto. O trabalho faz uma comparação entre a ocupação dos povos Nguni no sul de Moçambique, no começo do século XIX, e a ocupação portuguesa, no final do mesmo século. As consequências destas ocupações para os povos locais também foi levado em conta. Permeado de similitudes e diferenças estas ocupações carregaram traços específicos e marcantes na construção do Estado Moçambicano. Outra discussão presente nesta proposta diz respeito às formas de dependência que estiveram presentes em Moçambique, classificadas nas categorias de escravidão doméstica e a escravidão ligada ao modo de produção capitalista. Também se ressalta a relação da escravidão com o tráfico ultramarino, o qual acirrou esta prática e desestruturou a organização de muitos grupos regionais.

Palavras-Chave: Moçambique; Ocupação; Escravidão.

Abstract: The intention of this text is discuss about the occupation and the slave trade in Mozambique during the nineteenth century. The work will bring a balance between the occupation of the Nguni in southern Mozambique, at the beginning of the nineteenth century, and the Portuguese occupation, at the end of the same century. The consequences of these occupations for the local people will also be taken into account. Permeated the similarities and differences, these occupations carried specific traits and striking in the construction of the Mozambican State. Another discussion present in this proposal concerns the Forms of Dependency that were present in Mozambique, in categories of domestic slavery and slavery linked to the capitalist mode of production.

\footnotetext{
${ }^{1}$ Este texto é o produto de um trabalho final na disciplina de "Tópicos Especiais em História da África", ministrada no Departamento de História, pelo Professor Hector Guerra Hernandez

${ }^{2}$ Mestre em Educação pela Universidade Federal do Paraná.
} 
It also emphasizes the relationship of slavery to trafficking overseas, which intensified this practice and disrupted the organization of many regional groups.

Key-words: Mozambique, Occupation, Slavery.

\section{Introdução}

O presente texto tem a pretensão de discutir comparativamente os processos de ocupação da região sul de Moçambique ${ }^{3}$, feita pelos Nguni, antes da chegada dos colonizadores europeus, com a ocupação efetiva iniciada em 1895 pelos portugueses. Os impactos destas ocupações são o objeto desta análise dando um enfoque especial para as práticas de reprodução doméstica da região, das quais sobressaem a escravidão e a cobrança de tributos.

\section{Processos de ocupação: angunizados e colonizados}

No Sul de Moçambique o início da ocupação Nguni, povo originário de Natal, se deu na década de 1820. Após rivalidades com os Zulus, o líder Nguni chamado Sochangane (ou Manicusse) iniciou os primeiros ataques com incursões e saques a esta região. Os embates na região continuaram com o enfretamento aos portugueses e outros

3 Limites que relativamente conformam hoje as províncias de Maputo, Gaza e Inhambane. 
Revista Vernáculo, $n^{\circ} 30,2^{\circ}$ sem/2012

grupos inimigos rumo ao norte e oeste, caracterizando o Mfecane ${ }^{4}$. Desta forma, o Estado de Gaza formado por Sochangane configurou-se territorialmente entre os rios Incomáti e Zambeze.

${ }^{4}$ O Mfecane foi um movimento de dispersão e expansão Nguni (PÉLISSIER, 1987). O início do Mfecane foi com a Batalha de Gokoli, onde se enfrentaram os exércitos de Chaka Zulu contra os guerreiros de Zwide dos Ndwanwe. Depois de derrotar Zwide, os Ngunis de Chaka continuaram sua migração para o norte e oeste (FRELIMO, 1971). 
Revista Vernáculo, $n^{\circ} 30,2^{\circ}$ sem/2012

MAPA II. Mapa etnográfico simplificado (século XX)

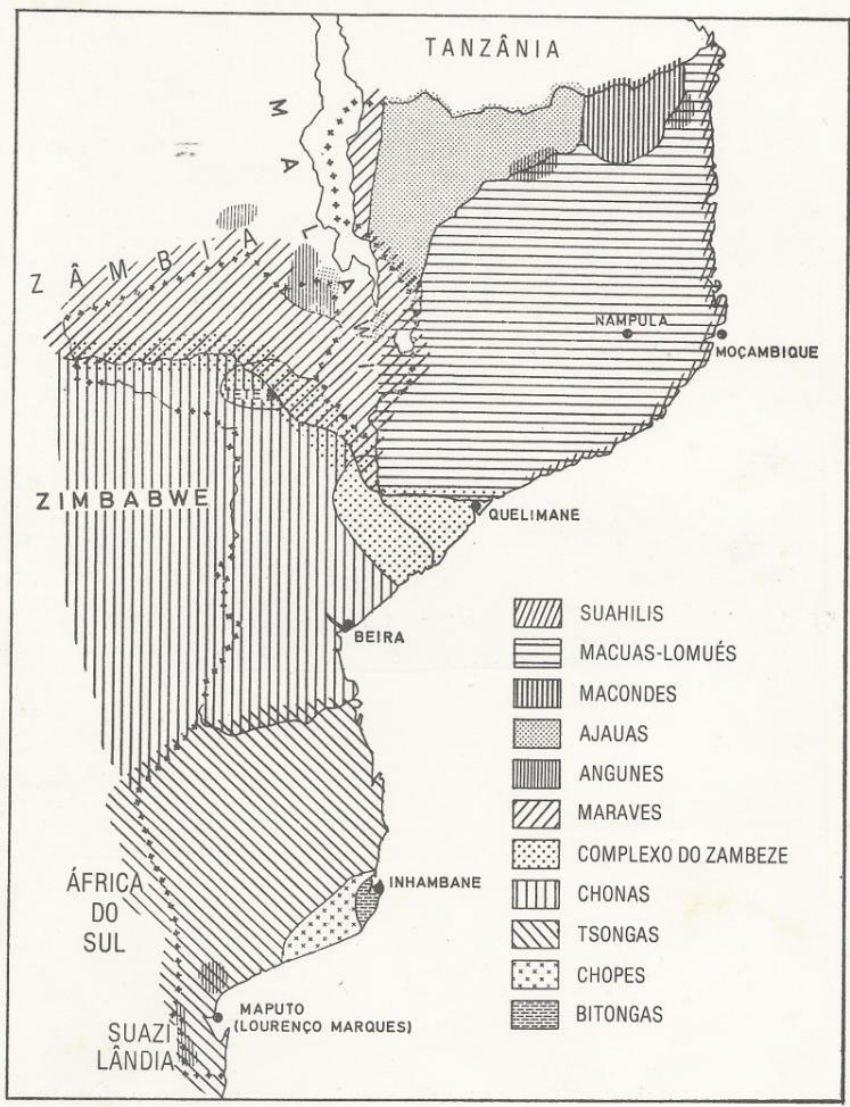

Fontes: Segundo Allison Butler Herrick et al., Area Handboòk for Mozambique, Washington, 1969, p. 60 e António Rita-Ferreira, Agrupamento..., op. cit., p. 16 \& Povos..., op. cit., p. 11 .

Rita-Ferreira (1982) afirma que desde o século XVI foram se configurando diversas comunidades dispersas no território conhecido 
por Moçambique, entre elas os Macuácua, Nkuna, Valoi, Hlengwe, Khosa, etc., que após a chegada dos Nguni e de um processo de assimilação tornaram-se hoje conhecidos como Changana. Junod, missionário suíço que defendia teorias de igualdade e a causa dos africanos contra os brancos, também fez um relato pormenorizado dos rituais, configurações familiares, hierarquias de poder, tabus e outros elementos desses grupos, reunindo-os sob o rótulo de Tsonga ${ }^{5}$, a partir de relatos orais e observações etnográficas. É interessante lembrar que os escritos de Junod são baseados em observações feitas após estes grupos terem sido angunizados ${ }^{6}$, ou seja, após terem interagido com elementos da cultura dos invasores Nguni. Rita-Ferreira (1982) também fala de outros dois povos presentes no sul de Moçambique que sentiram modificações em suas estruturas após a presença dos Nguni. Eram eles os Chopes e os Bitongas, localizados principalmente na atual província de Inhambane. Uma parcela dos Bitongas fugiu dos Nguni e buscaram refúgio entre os portugueses que possuíam uma pequena feitoria em Inhambane, na região costeira do seu território, os Chopes ao contrário, resolveram ficar em suas terras, e foram dizimados por Gaza. Em

\footnotetext{
${ }^{5}$ Vide: H. Junod, Uso e Costumes dos Bantus, Tomo I e II, Arquivo Histórico de Moçambique, Maputo, 1996.

${ }^{6}$ Para uma visão pormenorizada deste aspecto, vide GUERRA, Hector: Invasões estrangeiras e formação do estado ao sul de Moçambique. 2013, no prelo
} 
grande número estes Chopes foram escravizados e vendidos pelos Nguni. Outro povo que também passara por este processo de angunização fora os Tshwa.

Com a morte de Sochangane em 1858, uma instabilidade política tomou conta do reino por conta das disputas em torno da sucessão entre dois irmãos herdeiros. Muzila perseguiu o sucessor Mawewe e o derrotou em 1861, com ajuda logística dos portugueses localizados na feitoria de Lourenço Marques (hoje Maputo). Muzila também empreendeu grandes conquistas e reinou até 1884 . O próximo da linhagem foi Ngungunhana, o qual conquistou este espaço matando seus outros quatro irmãos? ${ }^{7}$. No reinado desse último há um olhar internacional mais aguçado para as riquezas e localização geopolítica dessa região, principalmente por parte dos ingleses (em particular pelo empresário e dono da British South African Company, Cecil Rhodes). Desta forma Portugal tenta alguns contatos diplomáticos com Gaza visando à exploração do ouro e do marfim, inclusive um tratado de "amizade e cooperação" é produzido, mas por ter suas cláusulas alteradas, tornando a cooperação em vassalagem, é negado em Gaza (LIESEGANG, 1986). Em 1889, devido à instabilidade política e a insegurança alimentar produzida por uma serie de conflitos na região ao

\footnotetext{
${ }^{7}$ De acordo com Liesegang (1996) não existe muita informação sobre os outros herdeiros à sucessão de Muzila.
} 
norte do Save, a capital de Gaza foi transferida para o baixo Limpopo, na região de Majacaze ${ }^{8}$. A investida para desestruturar Gaza aumentou por parte dos portugueses, e após várias batalhas ${ }^{9}$ em 1895 Ngungunhana foi capturado e levado para Portugal. Magigwane Khosa, o chefe do exército de Ngungunhana até tentou uma revolta reivindicando a volta do $\mathrm{rei}^{10}$, mas sem sucesso (PÉLISSER, 1987; NHACALE e MALUANA, 1997; COVANE, 2001).

Rita-Ferreira problematiza o fato de um exército tão grande como o de Ngungunhana (cerca de 15.000 soldados) ter sido derrotado por pouco mais de 1000 homens a serviço da Coroa Portuguesa. Tentando entender o ocorrido, o etnólogo e historiador ${ }^{11}$ alegou que além da diferença estritamente tecnológica armamentista, a fragmentação entre os chefes de Gaza, os quais estavam descontentes

\footnotetext{
${ }^{8}$ Ngungunhana muda com toda sua corte (milhares de Nguni e angunizados) em meados de 1889 devido à fome que assolava a antiga capital no centro do atual Moçambique.

${ }^{9}$ Primeiro teve a batalha de Magule, onde os portugueses venceram dois chefes de Gaza e incendiaram as residências circunvizinhas. E por fim, após a batalha de Coolela, Chaimite ( Manjacaze) ocorreu a prisão de Ngungunhana, que foi levado para Portugal, para logo morrer no exilio nas Açores.

${ }^{10}$ A guerra de Umbuyiseni, as declarações dos revoltosos era "Umbuysene Nkosi”, ou seja, devolvam o rei (NHACALE e MALUANA, 1997).

${ }^{11}$ António Rita-Ferreira foi um administrador colonial que ficou em Moçambique até depois da independência, em 1975. Seus trabalhos hoje são uma referência necessária para os estudos sobre a região sul deste país.
} 
com a política aplicada por Ngungunhana, teria ajudado na derrota do chefe Nguni.

Ao voltar o olhar para os períodos de conquista dos Nguni encontra-se a resposta das populações que eram integradas ao reino, bem como as transformações de ordem social, política e econômica na região. Quando chegavam aos povoados, os Nguni resumidamente cobravam tributos, se apropriavam do gado e das mulheres e os rapazes eram incorporados ao seu exército. Não havia devastação, mas a incorporação da população sob tributação e muita pressão políticoadministrativa, e isto gerava o descontentamento tanto da população quanto dos chefes incorporados (SERRA, 1983; RITA-FERREIRA, 1982). O exército Nguni quando chegava saqueava o que podia, principalmente o alimento disponível. Isto gerou transformação da base alimentar de algumas comunidades que "deixaram de cultivar arroz ou substituíram o cultivo de milho pelo de meixoeira (...) com a vantagem (...) de não ser apreciada pelos Nguni" (SERRA, 1983, p.104). RitaFerreira (1982) afirma que os guerreiros Nguni eram vistos como uma espécie de praga de gafanhotos. E esta economia baseada na pilhagem gerou rapidamente o esgotamento dos recursos e uma resistência passiva das populações que passaram a produzir menos. Outra resposta da população à pressão Nguni foi que já no reinado de Muzila, alguns 
Revista Vernáculo, $n^{o} 30,2^{\circ}$ sem/2012

homens começaram a migrar para a África do Sul em busca de trabalho (RITA-FERREIRA, 1982) $^{12}$

Quanto às transformações culturais têm-se registros de que os Macuácua depois de angunizados até aboliram a circuncisão. Uma das estratégias dos portugueses foi à espionagem nos povoados sob o domínio Nguni, desta forma teriam descoberto o descontentamento de alguns chefes e povoados com a pressão exercida pela administração de Ngungunhana. Assim sendo, uma das táticas dos colonizadores portugueses na ofensiva contra Gaza foi cooptar estes chefes tanto com armas de fogo, quanto com armas políticas (SERRA, 1983, p.98).

A presença portuguesa na costa do sul de Moçambique data ainda do século XV. Mas nos primeiros séculos, a ocupação do território foi tímida e limitada às regiões costeiras (LIESEGANG, 1995). Segundo Pélisser (1987) a presença portuguesa no interior do sul de Moçambique não foi muito influente durante o reino de Gaza, ainda que neste período houvesse incursões portuguesas em busca de marfim no interior (NEVES, 1987) e o envolvimento no pequeno tráfico de escravos (NEWITT, 1997). Foi no final do século XIX, com a derribada de Ngungunhana que começaram a ser implementados mecanismos de

\footnotetext{
12 Plantações e algodão no Natal e a partir de 1870 a produção de diamantes na região de Kimberly, nas proximidades do Estado livre de Orange.
} 
dominação que objetivavam uma ocupação militar e administrativa, ainda mais abrangente e eficaz. Segundo Zamparoni (1998) esta ocupação, somada a novas instituições, lançou-se mão de instituições e agentes políticos já presentes na sociedade sulista, sendo assim, usaram ao seu favor "régulos, indunas, interpretes e sipaios" (ZAMPARONI, 1998, p.127). Para a edificação de estradas e construções públicas ou particulares, os colonizadores se valeram do trabalho compelido (chibalo). Nesta dinâmica afirmavam que obrigando os africanos a trabalharem estariam regenerando-os moralmente. Para tanto criaram aportes legais que os permitiam prender e se valer do trabalho, quase gratuito, quase escravo, de homens que não pagassem o imposto de palhota (imposto cobrado por palhota habitada em espécie ou gênero, quando em dinheiro o valor era abusivo e quando em gênero valorandoo com o preço menor que o do mercado), que cometessem crimes ou que estivessem simplesmente desempregados. Apesar de pressões internacionais e mudanças na legislação para que este tipo de exploração cessasse, na prática quase nada mudou, e os moçambicanos continuaram sendo explorados ao longo do século $\mathrm{XX}$, com castigos corporais (cavalo marinho); alimentação precária; abuso de mulheres e crianças; longas jornadas; aprisionamentos de trabalhadores para trabalharem em obras públicas ou particulares sob a alegação de 
vadiagem, nem sempre verídica, tanto que se promoviam rusgas noturnas capturando homens e mulheres dentro de suas casas e depois falseavam alegações de vadiagem, etc. (ZAMPARONI, 1998).

Quanto à resposta da população à investida portuguesa de ocupação, já nos primórdios do século $\mathrm{XX}$, pode-se notar que tais práticas foram severamente criticadas pelos jornais "O Africano" e mais tarde "O Brado Africano" "13 em relação ao trabalho compelido (chibalo), o recrutamento militar compulsório e até mesmo o imposto de palhota. Outras articulações estiveram presentes como a Revolta do Barué, em $1917^{14}$. Muitos homens e suas famílias fugiram para as áreas menos fiscalizadas, ou partiam para o trabalho migratório em outras regiões, particularmente para a África do Sul (ZAMPARONI, 1998). Além de ser uma forma de resistência ao colonialismo, Lubkemann (2004) aponta que o trabalho migratório também permitiu um reajuste nas posições sociais, pois os jovens com seus salários conseguiam maior

\footnotetext{
13 É interessante observar que a redação destes jornais estava a cargo de um contraditório elenco, os quais combatiam com palavras os abusos relacionados ao trabalho forçado, e ao mesmo tempo faziam parte de uma pequena burguesia moçambicana que ocupava cargos de chefia nos mesmos lugares que os homens eram forçados a trabalhar para o governo. Como é o caso de João dos Santos Albasini, editor dos dois jornais e também supervisor da mão de obra africana do porto (PENVENNE, 1993, ZAMPARONI, 1998).

${ }^{14}$ Barué localiza-se no Tete, na região do Zambese, as principais causas da Revolta foram o recrutamento compulsivo da mão-de-obra sem remuneração e de forma abusiva para a construção de estradas.
} 
independência em relação aos mais velhos, principalmente nas decisões relacionadas ao casamento, instituição fundamental para a reprodução social das comunidades.

Em relação às transformações na estrutura social, política e econômica, geradas pelos portugueses, observou-se que com o uso de régulos e seus sipaios na administração colonial houve uma inversão de representações, pois antes estes líderes representavam e defendiam o seu povo, e depois se tornaram agentes do aparelho colonial português (ZAMPARONI, 1998). Uma das transformações da estrutura social e também econômica da população nativa foi o uso das mulheres no trabalho compelido, pois como elas tinham trabalhos específicos na sua comunidade, sua saída gerou uma desestruturação no ciclo reprodutivo doméstico. Outro aspecto de desestruturação foi que com os salários obtidos nos trabalhos migratórios, os homens investiram em "arados, charruas e juntas de bois" (ZAMPARONI, 1998, p.123; PENVENNE, 1993), isto levou a uma nova divisão social do trabalho, pois como o manejo com o gado era uma atividade exclusivamente masculina, foi este quem passou a fazer parte do plantio, função antes feminina. Não só os homens adquiriram novas funções, como também as mulheres, quando seus maridos iam para o trabalho migratório elas tinham que fazer o trabalho deles (COVANE, 2001). Outra transformação na 
estrutura social segundo Penvenne (1993) foi que tanto o trabalho compulsório, quanto o recrutamento militar forçado impeliram muitos a migrarem clandestinamente, isto somado às doenças e vícios provocou um grande despovoamento em extensas áreas no sul de Moçambique. A mesma autora também afirma que o chibalo gerou a desfragmentação e falta de solidariedade entre os grupos tradicionais.

Ao se procurar as semelhanças entre as ocupações Nguni e portuguesas pode-se destacar que as duas foram tentativas de centralização de um poder que dominou uma grande variedade de grupos, os quais atacaram. As duas formas organizaram-se militarmente para este intento. Os dois poderes cobraram impostos dos povos dominados. Os dois se valeram dos régulos para a fiscalização local dos seus regulados e cobrança de impostos.

E por fim podem-se pontuar algumas diferenças entre estes dois empreendimentos. Há diferenças evidentes entre estas duas formas de ocupação. Primeiramente porque o Estado de Gaza aplicou, sob um principio redistributivo, uma política de incorporação e assimilação das populações locais vencidas, a qual permitiu uma mobilidade social continua, enquanto os portugueses optaram por uma política assimilacionista que visava tornar os africanos em sujeitos dependentes e sem direitos garantidos, além de fragmentar suas relações sociais 
tradicionais. Por meio do que foi relatado, pode-se perceber que o Estado colonial foi muito mais explorador, no sentido de que, na lógica de acumulação que sustentou sua administração, toda a riqueza que pretendia adquirir em Moçambique era para ser levada para a metrópole. Enfim, o colonialismo português atuou como um elemento agressivo, explorador e desestruturador no sul de Moçambique.

\section{Formas de dependência e escravidão}

No período abrangido foi possível identificar duas das principais formas de escravidão encontrada em Moçambique ao longo de sua história passível de ser documentada: o sistema social chamado por alguns autores de escravidão doméstica e o sistema de tráfico ligado ao modo de produção capitalista.

No cativeiro tradicional na região norte de Moçambique no período pré-colonial predominava a escravidão doméstica, a qual era na maioria das vezes apreciada tanto pelo senhor quanto pelo escravo, pois este via nesta uma situação de proteção e refúgio. Capela (2002) traz o exemplo da pesquisa de Rita-Ferreira (1996) na qual descreve que entre os Cheuas de Macanga, os homens escravizados eram muitas vezes eleitos esposos das filhas do senhor e as mulheres escravizadas também 
tinham grandes chances de tornarem-se esposas do senhor. Nestes exemplos percebe-se que os cativeiros tradicionais eram integradores e "não implicavam nem mercantilismo nem exclusão definitiva" (CAPELA, 2002, p.14). Meillassoux descreve a reprodução doméstica como aquela em que a comunidade estabelece meios de produção e uso da terra para a subsistência do grupo (1987, p.67). A reprodução seria a preocupação dominante neste sistema social. Para tanto, a mulher exerceria aí um papel fundamental de produção (agrícola) e reprodução (descendentes). Desta forma, para garantir a reprodução estrutural da comunidade doméstica era necessário:

a cooptação de membros nascidos fora da comunidade. A adoção de crianças de uma linhagem por outra, de cativos de guerra, de clientes, de forçados, por vezes o dote de uma esposa ou o rapto de mulheres, as fusões entre famílias debilitadas são os meios para corrigir um equilíbrio sempre precário (MEILLASSOUX, 1987, p.82).

Esta busca pelo elemento de fora que ajuda na produção e reprodução do grupo deu margem para que se estabelecesse um sistema social de escravidão doméstica, na qual segundo Capela (2002, p.13) o escravo era incorporado/integrado ao grupo. A este tipo de escravidão que incorpora o indivíduo a uma linhagem, Watson (1980) chama de 
escravidão como instituição aberta. Também a escravatura em Moçambique foi por vezes chamada de simbiótica (CAPELA, 2000), pois muitos homens vendiam a si próprios em troca de tecidos, aguardente, proteção, ou até mesmo o livramento de uma pena de sentença de morte. Este fenômeno ficou conhecido como "corpo vendido" e era recorrente, principalmente, no século XIX. E como afirma Capela (2000) esta era uma situação de refúgio diante da ameaça do desterro ou a morte. Isto fez com que muitos prazeiros ${ }^{15}$ se aproveitassem do costume para se apropriarem de homens e mulheres e vendê-los para a exportação. No entanto, esta prática era recorrente dentro do país, sendo que os escravos temiam muito mais o desterro do que a própria morte (CAPELA 2002). Havia também hierarquias neste tipo de escravidão, como os butacos, os quais eram uma categoria de escravos que também eram senhores, pois eram proprietários de bens e de homens (CAPELA, 2002; 2000).

Já a escravidão ligada a um modo de produção capitalista, cujo tráfico se avoluma desde finais do século XVIII, está intimamente ligada com o tráfico e estabelece uma relação com o escravo que era

\footnotetext{
${ }^{15}$ Prazeiros eram os colonos que possuíam os prazos, ou seja, faixas de terra para o cultivo, exploração e que também serviram de acantonamento de escravos. Estes surgiram no século XVII e a posse de terra por era dada por aproximadamente três gerações. A maior parte dos prazos localizava-se no vale do rio Zambeze.
} 
totalmente contrária à de parentesco, pois o escravo neste caso era tido juridicamente como um bem móvel (PATTERSON, 2008). E o maior objetivo visado era o lucro através da apropriação da sua força de trabalho, por isso que em muitos casos, como destaca Meilassoux (1986), o escravo foi privado de ter filhos, pois a alimentação da prole diminuiria os lucros. E dessa forma a manutenção deste tipo de escravidão se dava pela captura sistemática de novos escravos. E isto denota uma diferença discrepante com as formas de cativeiro doméstico, na qual as mulheres cativas eram utilizadas para a reprodução do grupo que a escravizava. Enquanto na comunidade de reprodução doméstica o escravo produzia para a subsistência do grupo e participava dos benefícios desta produção, na escravidão como modo de produção o uso da força de trabalho do escravo era intenso e em larga escala. Enquanto no sistema de reprodução doméstica havia o convívio com outros sistemas, no modo de produção a escravidão era a base da economia. E neste caso, em vez do escravo ser integrado ele era totalmente excluído de qualquer direito, inclusive de sua própria sexualidade.

Agora o foco da discussão será na relação da escravidão com o tráfico ultramarino de escravos. A princípio, particularmente a partir do 
século XVII, os escravos eram vendidos para o Oriente ${ }^{16}$, especialmente para as Ilhas do Oceano Indico, nas zonas de plantação principalmente francesas. Nestas Ilhas, a relação foi de trabalho intenso em lavouras e outras funções (cana, café, cravo da índia, etc.), característica do modo de produção escravocrata. A relação da escravidão com o ultramar era tão forte e lucrativa que mesmo em momentos de proibição continuou. Portugal (1836) e a França (1848) aboliram oficialmente a escravidão em suas colônias. Mas isto não foi obstáculo para o tráfico clandestino por parte de navios franceses, sob a conivência das autoridades portuguesas nos postos administrativos litorâneos. Este tráfico criou uma nova roupagem, aos homens que partiam de Moçambique dava-se o nome de engagés (kaporos), os quais exerceram trabalhos exploratórios sob o signo de libertos. No entanto as condições com que o tráfico era feito continuaram as mesmas (CAPELA, 2002). Mesmo com proibições e restrições havia uma rede que continuava o tráfico na ilegalidade e escravos eram trocados por bagatelas (MEDEIROS E CAPELA, 1987).

É interessante perceber que houve diferenças na escravidão configurada ao norte do rio Save em relação ao sul. Na região norte do

\footnotetext{
${ }^{16}$ Antes da chegada dos europeus já havia rotas de comércio estabelecidas entre Moçambique e os árabes, persas e indianos (CAPELA, 2002)
} 
rio Save pode-se destacar as formações sociais dos Macuas-lómuè, Ajauas (Yao), Cheuas-nianjas, Macondes, etc., onde estavam localizados os mais importantes reservatórios de escravos para o tráfico de ultramar. Antes do tráfico, particularmente os Macua-lómuè, eram constituídos por comunidades reprodutivas dispersas, caracterizadas por linhas de sucessão maternas (grupos matrilineares) e casamentos exogâmicos. Estas comunidades tinham nomes diferentes, mas mantinham a crença numa origem comum (nos Montes Namúli). Nas linhagens, elementos exteriores eram incorporados através do penhor, compra, rapto e até mesmo o pedido de cativeiro (MEDEIROS \& CAPELA, 1987). Com o desenrolar constante do tráfico orientado para a exportação nas ilhas do índico, formaram-se as grandes chefaturas, os cativos que antes eram tratados como pessoas (nihimo dos donos) passaram a ser considerados coisas (akanihimo) ${ }^{17}$. A busca frenética por escravos para o tráfico fez com que as razias e raptos aumentassem, suscitando levas de migração e reagrupamentos. Segundo Medeiros e Capela, o tráfico perturbou tanto a caça de escravos que começou a ser feita no "interior do próprio grupo tribal e da chefatura" (1987, p.98),

\footnotetext{
${ }^{17}$ Segundo Medeiros e Capela (1987) o termo nihimo designa a identificação do indivíduo com seu clã matrilinear de origem. É interessante observar que na cosmovisão dos macuas-lómué um cativo era tratado, tradicionalmente, como uma pessoa que não perdia seu nihimo. Este status se perdeu com o tráfico de escravos.
} 
Revista Vernáculo, $n^{o} 30,2^{\circ}$ sem/2012

assim, os próprios parentes eram vendidos, principalmente os sobrinhos, pois ameaçavam o poder dos chefes por causa da sucessão. Estigmas (escarificações) foram usados para marcar os escravos e evitar fugas, mas também para identificar os membros do mesmo grupo. A crueldade e a violência se intensificavam cada vez mais, tanto que de medo "as mulheres não saiam praticamente das imediações da aldeia, e os homens não se deslocavam jamais senão em grupos, com as suas armas" (MEDEIROS \& CAPELA, 1987, p.108). Finalmente, pode-se notar que na região norte, como consequência do tráfico ultramarino, há uma quebra na fraternidade e solidariedade entre as diversas comunidades de origem. Com o modo de produção escravista estabelecido a demanda por escravos era cada vez maior, e até mesmo as organizações políticas dispersas dos clãs Macua sofreram uma centralização como estratégia de sobrevivência, pois a sociedade havia se dicotomizado entre caçadores e caçados. As migrações e a perda da população também geraram desestruturação econômica, pois faltavam trabalhadores para a produção agrícola doméstica.

$\mathrm{Na}$ região sul, pode-se afirmar que houve um tráfico menor do que no norte. Isto porque os Nguni, apesar de terem vendido alguns cativos no começo do reino, mostraram-se depois hostis a esta prática, pois preferiram incorporar os vencidos aos seus exércitos ou como 
trabalhadores em suas plantações. O próprio Manicusse proibiu a escravatura comercial, diferente dos Rongas e dos Bitonga, que aderiram à prática da venda exterior de homens. Rita-Ferreira (1982) afirma que no contexto cultural dos "Tsongas" houve um papel relativamente reduzido no comércio de escravos fomentado pelos traficantes europeus e asiáticos. O mesmo autor traz um ponto essencial que diferencia a prática do sul com a do norte, trazendo o dado que nesta região só se escravizava e se vendia o inimigo, enquanto que no norte até parentes eram vendidos.

Por fim, pode-se pensar que os colonos e traficantes subverteram as práticas de reprodução social das comunidades a partir do momento em que se apropriavam de homens que vendiam seu corpo para exportálos para outros lugares, nos quais em vez de proteção do senhor, integração a um novo clã e até mesmo livramento da morte, eram submetidos à exclusão social e ao tratamento violento e desumano. Como destacou Capela (2000) o escravo colonial moderno foi excluído tanto do seu grupo de origem quanto do grupo que dele se apropria. 
Referências

CAPELA, José. Escravidão e tráfico de escravos em Moçambique. IN:

O tráfico de Escravos nos Portos de Moçambique 1733-1904. Lisboa: Edições Afrontamento, 2002. P. 11-26.

CAPELA, José. O tráfico de escravos. IN: O tráfico de Escravos nos Portos de Moçambique 1733-1904. Lisboa: Edições Afrontamento, 2002. P. 27-66.

COVANE, L.A. O trabalho migratório e agricultura no sul de Moçambique. Ed. Promedia, Maputo, 2001. P.67-124.

GUERRA, H.. Invasões estrangeiras e formação do estado ao sul de Moçambique. 2013, no prelo

JUNOD, H. Uso e Costumes dos Bantus, Tomo I e II, Arquivo Histórico de Moçambique, Maputo, 1996.

LIESEGANG, G. A guerra dos reis Vátuas - do Cabo Natal, do Maxacane da Matola, do Macassane de Maputo e demais reinos vizinhos contra o Presídio da Baia de Lourenço Marques. 
Revista Vernáculo, $n^{o} 30,2^{\circ}$ sem/2012

Documentos. Arquivo Histórico de Moçambique. Maputo (reimpressão), 1995.

LIESEGANG, G. Vassalagem ou Tratado de Amizade? : história do acto de vassalagem de Ngungunyane nas relações externas de Gaza. Estudos. Arquivo Histórico de Moçambique, Maputo, 1986.

LOVEJOY, P. “A África e a Escravidão” In: A escravidão na África. Uma história das suas transformações. Ed Civilização brasileira, Rio de Janeiro, 2002, p.11-26.

LUBKEMANN, S.C. "Reduzir o colonialismo à sua real dimensão: a migração internacional entre os moçambicanos do Centro - Sul, 19901999. In: CARVALHO, C. \& CABRAL, J. D. P. A persistência da história: passado e contemporaneidade em África. Ed, ICS, Lisboa, 2004, p.253-306.

MARTINS, J. S. "Escravos e escravatura em Moçambique. Problemas identitários". Africania Studia. Nº 3 . Ed. Universidade do Porto, 2000. P.33-48. 
MEDEIROS, E. \& CAPELA, J. "Sistematização do tráfico para as plantações francesas. 1800-1854”. In: O tráfico de escravos para as ilhas do índico 1720-1902. UEM, Maputo, 1987, p.31-44

MEDEIROS, E. \& CAPELA, J. "Formas de efeito do tráfico na sociedade de servidão e comércio de escravos no norte de Moçambique". In: O tráfico de escravos para as ilhas do índico 17201902. UEM, Maputo, 1987, p.89-124.

MEDEIROS, E. "Contribuição da diáspora para a formação das identidades culturais nas ilhas do Oceano Indico. In: Travessias Revista da Associação de Ciências Sociais e Humanas em Língua Portuguesa. Rio de Janeiro, n²/3, 2002, p. 63-86.

MEILLASSOUX, C. "Lucros e acumulação". In: Antropologia da Escravidão. Jorge Zahar editor, Rio de Janeiro, p.68-77.

MEILLASSOUX, C. “A reprodução doméstica". In: Mulheres, Celeiros \&Capital. Editora Afrontamento, Lisboa, 1987, p.60-87.

NHACALE, Orlando. MALUANA, Castigo. Magigwane e Mbuysiseni. Alguns subsídeos para a reinterpretação da 
Revista Vernáculo, $n^{o} 30,2^{\circ}$ sem/2012

Historiografia da resistência Colonial do Estado de Gaza. Coleção Embondeiro, ARPAC, Maputo, 1997.

NEVES, Diocleciano Fernandes das. ROCHA, Ilídio. Das Terras do Império Vátua às Praças da República Boer. Lisboa: Publicações Dom Quixote, 1987. P.15-40

NEWITT, M. História de Moçambique. Lisboa, Publicações EuropaAmérica, 1997, p.140-157.

PATTERSON, O. "A linguagem do poder". In Escravidão e morte social. Edit. Edusp, São Paulo 2008. pp. 39-64

PÉLISSER, R. História de Moçambique. Formação e Oposição 1854-1918. Lisboa, 1987. Vol. I, p.111-125.

PENVENNE, J. Trabalhadores em Lourenço Marques (1870-1974). AHM, estudo 9, Maputo1993, p. 13-44.

SERRA, C. Para a história da arte militar moçambicana (1505-1920).

Cadernos Tempo. Maputo, 1983. PP.83-107.

RITA-FERREIRA, A. Fixação portuguesa e História pré-colonial de Moçambique. Lisboa, Instituto de Investigação Científica 
Revista Vernáculo, $n^{o} 30,2^{\circ}$ sem/2012

Tropica1/Junta de Investigações Científicas do Ultramar, "Estudos, Ensaios e Documentos", n. ${ }^{\circ} 142,1982$. pp. 185 - 232

RITA-FERREIRA, A. Presença Luso-asiática e mutações culturais no sul de Moçambique (até c.1900). Lisboa, Instituto de Investigação Científica Tropical/Junta de Investigações Científicas do Ultramar, "Estudos, Ensaios e Documentos", n. ${ }^{\circ} 139$, 1982. pp. 131 - 182

WATSON, J. Slavery as an Instituition: Open and Closed Systems. In: WATSON, J. Ed. Asian and African systens os Slavery.Brasil Blackwell, 1980.

ZAMPARONI, W. "O trabalho compelido: formas e dimensões". In.:

Entre Narros e Mulangos: Colonialismo e paisagem cultural em Lourenço Marques. c. 1890- c. 1940. Tese de Doutorado, USP, São Paulo, 1998, p.87-141. 